\title{
Prensa nacionalista vasca y emigración a América (1900-1936)
}

\author{
Óscar Álvarez Gila \\ y José María Tápiz Fernández \\ Euskal Herriko Unibertsitatea \\ Vitoria-Gasteiz
}

\begin{abstract}
Desde su nacimiento, la prensa nacionalista dedicó su atención al fenómeno emigratorio vasco hacia América, a través de una doble visión. Por un lado, asumió la concepción negativa de la emigración, siguiendo las pautas de la prensa del siglo XIX anterior al nacionalismo, al considerar que suponía una pérdida de brazos para el país. Por otro lado, esta presentación negativa quedaba compensada por el tratamiento de la difusión del nacionalismo vasco en América, que se realizaba desde ambos lados del Atlántico. En este artículo presentamos brevemente esta doble visión, así como una relación de los artículos que aparecen en la prensa nacionalista vasca entre 1900 y 1936 sobre la emigración a Amorica y la presencia y actividad de los vascos allí.
\end{abstract}

\section{Introducción}

El objeto del presente trabajo es ofrecer un material de sumo interés para el estudio de la emigración vasca a América $^{1}-\mathrm{y}$ sobre todo a Argentina -2 desde un punto de vista poco o nada estudiado: la opinión que, respecto a este fenómeno, se generó desde la visión de una de las ideologías políticas que ha marcado la evolución histórica del País Vasco en el siglo XX: el nacionalismo vasco.

Ciertamente, la presencia vasca en América fue, durante buena parte de los tiempos contemporáneos, cuantitativamente muy importante. La corriente migratoria que, a lo largo de buena parte del siglo XIX y el primer tercio del XX, experimentó el País Vasco, tuvo desde muy temprano reflejo en la prensa periódica, como objeto de análisis $\mathrm{y}$, muchas veces, de ataque.

El nacionalismo vasco, desde el mismo momento de su aparición, prestó una gran importancia a los movimientos migratorios que de modo simultáneo experimentaba el País Vasco, tanto de atracción — de otros lugares de España - como de expulsión — hacia América. Surgido en

1 Sobre emigración vasca a América, Douglass, W.A. y J. Bilbao: Amerikanuak. Basques in the New World, Reno (Nevada), 1975. Marenales Rossi, M.: La aventura vasca. Destino: Montevideo, Montevideo, 1991. San Sebastián, K. y P. Ajuria: El exilio vasco en Venezuela, Vitoria, 1992. 
Vizcaya durante la última década del siglo XIX de la mano de Sabino Arana Goiri, el nacionalismo vasco como ideología organizada también se dotó de sus órganos de expresión y opinión pública. Consciente de la importancia de la prensa escrita en la difusión de toda idea política, Arana dio el primer paso al respecto fundando, a fines del XIX, el periódico Bizkaitarra, que si bien no era diario — se publicaba aproximadamente dos veces al mes, sin fecha fija, en su primera época-, fue el primer ejemplo de prensa periódica nacionalista.

\section{La prensa nacionalista vasca: $1900-1936$}

\section{Desarrollo cronológico}

Con posterioridad a la muerte de Arana (1903), y debido al desarrollo del nacionalismo vasco como idea política y del Partido Nacionalista Vasco (PNV) como movimiento organizado, surgieron otra serie de publicaciones - unas diarias, otras de más amplia periodicidad- que, con mayor o menor suerte, ofrecían al lector una visión nacionalista de las noticias, la política y la vida misma. ${ }^{3}$ Así nacieron Gipuzkoarra (San Sebastián, 1907), Euzkadi (Bilbao, 1913), La Tarde (Bilbao, 1914), ${ }_{4}^{4}$ Aberri (Bilbao, 1923), ${ }^{5}$ Excelsior (Bilbao, 1924), ${ }^{6}$ y otros varios.

2 Azcona Pastor, J.M.: Los paraísos posibles. Historia de la emigración vasca a Argentina y Uruguay en el siglo XIX, Bilbao, 1992. El mismo,García-Albi, I., y F. Muru Ronda: Historia de la emigración vasca a Argentina en el siglo XX, Vitoria, 1992. Siegrist de Gentile, Nora: Inmigración vasca en la ciudad de Buenos Aires, 1830-1850, Vitoria, 1992.

3 Sobre la prensa vasca del período, véase Sainz Valdivieso, A. C.: Triunfo y tragedia del periodismo vasco (1900-1939), Madrid, 1977, y Tuñón de Lara, M. (ed.): Comunicación, cultura y política durante la II República y la Guerra Civil, Leioa, 1984, 2 vols.

4 La Tarde no nació como diario de los nacionalistas, aunque finalmente éstos terminaron controlando el diario en 1927 al conseguir sustituir a su director, el aragonés Saturnino Lafarga, por el nacionalista Eusebio Zuloaga.

5 Aberri pertenecía a un grupo escindido en 1921 del partido nacionalista —entonces denominado Comunión Nacionalista Vasca-, que tomó para sí el original nombre de PNV. Años más tarde ambas corrientes acabarían refundiéndose en la Asamblea de Vergara de 1930, bajo estas últimas siglas (De la Granja, J. L.: Nacionalismo y II República en el País Vasco, Madrid, 1986.

6 Excelsior — desde 1931, Excelsius - era un diario de información deportiva, el primero de estas características en España, por lo que, aunque integrado en el grupo editorial nacionalista, no era políticamente tan combativo como otros, debido en parte a que "venía a jugar como periódico-comodín del que podría echarse mano en el caso, siempre probable, de que a la Dictadura [de Primo de Rivera] le diera por suspender alguno de los rotativos de la Comunión Nacionalista" (Sainz Valdivieso, A. C.: Triunfo y tragedia... pág. 207). 
No todos los periódicos se presentaban combativamente nacionalistas en la misma medida; era distinto el caso de Euzkadi, por ejemplo, que el de Excelsior o La Voz de Navarra - otro de los periódicos pertenecientes al bloque nacionalista, publicado en Pamplona. Sólo el primero era el auténtico órgano de expresión oficial del partido aranista - llamado, por entonces, "Comunión Nacionalista"-, y se hallaba amparado por la editorial Euzko Pizkundia S.A., de carácter plenamente nacionalista; Euzkadi llegó a ser, en la década de 1930, el periódico de mayor difusión en el País Vasco, por delante de sus competidores de diferente ideología, como los diarios vizcaínos El Liberal, La Gaceta del Norte, El Pueblo Vasco, etc. ${ }^{7}$ Otros periódicos nacionalistas, por el contrario, fueron de corta vida (Gipuzkoarra desapareció en 1913), se transformaron en semanarios (Bizkaitarra), llevaron una vida lánguida por graves problemas económicos (La Voz de Navarra), o — sin más - se trataba de diarios de simpatías nacionalistas, pero sin una vinculación concreta con el partido.

\section{Fundamentación ideológica de la prensa nacionalista}

En los artículos y noticias referentes a América que relata la prensa nacionalista vasca, destaca ante todo un hecho que se corresponde con el núcleo central del mensaje político de esta ideología: la presentación del País Vasco (o Euzkadi, según el neologismo acuñado por el propio Arana) como una nación propia y diferenciada de España y Francia, estados en los que se reparte.

Los fundamentos de esta nacionalidad se apoyaban en cuatro columnas: raza, religión, lengua e historia. El criterio de raza — quizá sería mejor decir "etnia" - estaba presente en el proyecto nacionalista desde los tiempos de Arana ${ }^{8}$ el cual no hizo más que hacerse eco de las investigaciones etnológicas en boga por aquellos años, refrendadas en años posteriores por estudiosos como Barandiarán, Aranzadi, Eguren y otros. ${ }^{9}$ En sus trabajos se aludía a unas especiales características físicas de los vascos en algunas zonas del País, como por ejemplo la forma craneal. Para los seguidores de

7 Euzkadi tenía una tirada de 25.000 ejemplares diarios en 1935.

8 Sobre el particular, véase Corcuera, J.: Orígenes, ideología y organización del nacionalismo vasco (1876-1904), Madrid, 1979. Larronde, J.-C.: El nacionalismo vasco. Su origen e ideología en la obra de Sabino Arana Goiri, San Sebastián, 1977.

9 Biografía de Barandiarán, de Luis Barandiarán Irízar, en Barandiarán, J. M.: Obras completas, Bilbao, 1972-1973. 
Arana, esto constituía una de las pruebas irrefutables de la razón de ser del nacionalismo vasco, en consonancia con el modelo germánico de nacionalismo de Fichte y la escuela romántica, para quienes todo pueblo con características propias y diferenciadas de los de su alrededor era llamado a constituir un estado político independiente. ${ }^{10}$

$\mathrm{El}$ argumento de la religión no era, evidentemente, el de una diferencia de credo respecto a españoles y franceses — católicos ambos-, sino el de una religiosidad más profunda y arraigada en el ámbito vasco. El argumento lingüístico, por su parte, era evidente: el euskera o vascuence es una de las pocas lenguas europeas que no pertenece al grupo indoeuropeo, y del cual se desconoce su origen. ${ }^{11}$

En cuanto a la fundamentación histórica, el nacionalismo sostenía al igual que otras fuerzas políticas vascas- que las leyes que habían regido al País Vasco a lo largo de la historia - los Fueros - tenían un carácter de pacto con las Coronas castellana - núcleo de la futura española- y francesa. Por ello, la incorporación a dichas Coronas sólo se habría hecho en forma de unión personal en el monarca, y los Fueros no podían ser unilateralmente transformados. Las aboliciones forales, que tuvieron lugar en 1876 —o 1839, según los nacionalistas - en la vertiente española, y en 1789 en la francesa, habrían supuesto así la pérdida de la independencia secular de los vascos, objetivo por cuya consecución o "recuperación" había surgido el partido nacionalista.

\section{La visión nacionalista de los vascos de América}

Partiendo de lo señalado en el apartado anterior, pueden entenderse las constantes ideológicas — concretamente, tres-, a través de las cuales la prensa nacionalista desarollará una visión de la emigración y presencia vasca en América, propia de dicha ideología política.

\section{La necesidad de agrupamiento de la colectividad}

La primera de estas constantes fue la idea de la necesidad de que los emigrantes vascos en América se agruparan en sus países de radicación en

10 Kohn, H.: Historia del nacionalismo, México, 1949.

11 Mitxelena, Luis: "Sobre historia de la lengua vasca", Anejos del Anuario del Seminario de Filología vasca “Julio de Urquijo”, Usúrbil, 1988. 
sociedades y entidades única y exclusivamente vascas — los llamados genéricamente centros vascos-, de modo similar a las que habían formado en aquellas tierras los originarios de otros países europeos.

Bien es cierto que ya había comenzado a surgir este tipo de asociacionismo antes del nacimiento organizado del nacionalismo; la primera de las sociedades de carácter vasco — la "Sociedad Vasco-Navarra de Socorros Mutuos" de La Habana, en Cuba- ya existía desde la década de 1860, y en la siguiente surgieron los primeros centros vascos de Argentina y Uruguay —ambos con el nombre de "Laurak Bat". ${ }^{12}$ Sin embargo, para el nacionalismo vasco el concepto de agrupamiento iba más allá de simples objetivos recreativos, nostálgicos o asistenciales: surgían de la necesidad de defender y preservar entre los emigrantes la cultura patria, la lengua y las costumbres vascas. ${ }^{13}$ En definitiva, se trataba de que los vascos lejos de su patria siguieran siendo vascos, fomentando su conciencia de "nación", en igual medida que polacos, italianos, alemanes, etc... Por ello, los nacionalistas criticarán el poco "espíritu nacional" de las entidades vascas presentes en Hispanoamérica -y sobre todo las de Argentina, Uruguay y Chile, países en los que el nacionalismo hizo esfuerzos de implantarse organizativamente-; en ellas, señalan, por desgracia sólo se va a jugar pelota vasca, a dedicar tardes al mus y a hablar de la vida en su pueblo natal. ${ }^{14}$

Este reagrupamiento de los vascos que defendía el nacionalismo tenía a su vez un carácter "medicinal": con ellos se conseguiría la preservación de los caracteres de la raza vasca en los nuevos territorios americanos. Para ello, el método más efectivo era el establecimiento de lazos de solidaridad ${ }^{15}$ de todo tipo - que llegasen hasta la endogamia - entre los inmigrados, lazos que eran tanto más fáciles de realizarse en las aglomeraciones importantes donde existía un número suficiente de vascos o de descendientes directos de éstos. No en vano se calculaba que, en el primer tercio del XX, residían en América 400.000 vascos e hijos de vascos —una notable cifra,

12 En euskera, Las cuatro, una, en referencia a la unidad de las cuatro provincias con población originaria vasca de España: Álava, Guipúzcoa, Navarra y Vizcaya.

13 Aranzadi, Engracio de, "Kizkitza": Euzkadi, 8 de mayo de 1928. En la prensa nacionalista fue muy usual la utilización de pseudónimos por parte de sus habituales colaboradores.

14 Etxeberria, Isaac de: Euzkadi, 11 de marzo de 1931.

15 Urrutia'tar, Rikarta: "Carta de Cuba", Bizkaitarra, 6 de mayo de 1909. Berroeta Aldamar: "Desde México", Bizkaitarra, 22 de enero de 1910. Gandiaga Loyola, Ander: "Euzko Etxea", Euzkadi, 28 de agosto de 1913. 
frente al casi millón y medio de habitantes que tenía Euskal Herria por aquellos años. ${ }^{16}$

Otro frente que cubrió la prensa nacionalista, siempre con la intención de favorecer la unión entre los vascos de América y el mantenimiento de una colectividad unida, fue el de potenciar las fiestas "nacionales" y otros actos colectivos de carácter plenamente vasco allá realizados. Sobre todo, fue especial el reflejo que tuvieron las conmemoraciones anuales de la festividad religiosa de San Ignacio de Loyola, ${ }^{17}$ guipuzcoano y co-patrono por entonces de la diócesis vascongada de Vitoria [Álava, Guipúzcoa y Vizcaya], juntamente con la de San Miguel Arcángel ${ }^{18}$ —en su doble función de patrono de Navarra y del propio PNV. El paroxismo llegaba a la hora de reflejar incursiones más marcadamente políticas en estos actos socio-religiosos, como ocurrió con la bendición de sendas ikurriñak (banderas vascas) en el centro "Laurak Bat" de Buenos Aires en $1921^{19} \mathrm{y}$ en el centro "Euskal Herria" de Montevideo en $1934 ;{ }^{20}$ o cuando había que reflejar los actos organizados por entidades de filiación nacionalista instaladas en América, como el centro "Euzko Gaztedija" ${ }^{21}$ de Santiago de Chile ${ }^{22}$ o el "Zazpirak Bat" ${ }^{23}$ de Rosario, en Argentina. ${ }^{24}$

\section{La necesidad de extensión del mensaje nacionalista entre los vascos americanos}

Esta última referencia nos pone en la pista de lo que, para la prensa nacionalista vasca, fue la segunda constante de su visión sobre la emigra-

16 Concretamente, las cuatro provincias del País Vasco español tenían, en 1930, 1.237.593 habitantes, correspondiendo casi medio millón a Vizcaya. García-Sanz Marcotegui, Ángel: "La evolución demográfica vasca en el siglo XIX (1787-1930). Tendencias generales y contrastes comarcales de la nupcialidad y fecundidad", Segundo Congreso Mundial Vasco. Congreso de Historia de Euskal Herria, San Sebastián, 1987, tomo IV, págs. 19-41.

17 Euzkotarra: Euzkadi, 6 y 9 de diciembre de 1913.

18 Koldobika, Euzkadi, 1 de enero de 1936.

19 Astigarraga, Andoni de: Abertzales en la Argentina, Bilbao, 1984.

20 Entre otros, Euzkadi, 13 y 14 de octubre de 1933 y 25 de enero de 1934.

21 "Juventud Vasca" en euskera.

22 Lantzi: Euzkadi, 4 de mayo de 1933. Id., 7 de enero de 1934.

23 Las siete, una, en referencia a la unidad de todo el País Vasco, tanto las cuatro provincias vasco-españolas como las tres históricas de la parte francesa.

24 Álvarez Gila, Óscar: "Euskal abertzaletasunaren ezarrera Argentinan: Rosarioko Zazpirak Bat euskal etxearen adibidea (1912-1935)" [La implantación del nacionalismo vasco en Argentina: el ejemplo del centro vasco Zazpirak Bat de Rosario (1912-1935)], Mundaiz, 44, San Sebastián, 1992, págs. 97-117. 
ción y presencia vasca en América: la implantación y extensión entre los emigrantes de la ideología nacionalista, tanto como ideario político como institución organizada alrededor del partido. Resultaba claro que, en el contexto antes descrito, el proceso de unión dentro de lo verdaderamente vasco exigía, sobre todo, un brazo rector que marcase claramente el objetivo de construcción de la nacionalidad que llevaba tras de sí, a través del establecimiento de una sólida estructura institucional nacionalista, especialmente en aquellos países donde la colonia vasca era más numerosa. ${ }^{25}$

1.- - Por esta razón, en un primer momento había que diferenciar lo que era real y plenamente vasco, de los caracteres ajenos a su ser y que, en la visión nacionalista, habían adulterado el ser nacional. La prensa nacionalista reflejará esto a través de un cambio semántico en la propia definición de "vasco", que adquirirá connotaciones especiales en boca de los nacionalistas, y que rápidamente pasó a traducirse a la realidad vasco-americana. Hasta fines del siglo XIX puede decirse que tanto "vasco" como "vascongado" eran dos adjetivos con un grado notable de sinonimia, que reflejaban ante todo la pertenencia a un mismo grupo étnico-cultural, con ciertos matices de tipo geográfico. ${ }^{26}$ En los círculos nacionalistas, "vascongado" —o "vascuence"- adquirió progresivamente un matiz peyorativo: éste sería, a diferencia del auténtico "vasco" comprometido con su patria y su raza, un renegado que se adhiere a posturas políticas españolistas o - menos- profrancesas. Ya para inicios de la década de 1920 comienza a observarse en la prensa referida a los vascos de América esta diferenciación al relatarse los enfrentamientos entre nacionalistas y no nacionalistas por el control de los centros vascos de Argentina. ${ }^{27}$ Para inicios de la década siguiente, esta diferenciación semántica se hallaba ya claramente establecida. ${ }^{28}$

2.-Este cambio semántico, como es lógico, no podía dejar de tener consecuencias en la visión que la prensa nacionalista ofrecía sobre la emigración "vasca" y sobre la formación de la "auténtica colectividad vasca" en los diferentes países americanos. Sobre el proceso emigratorio en gene-

25 Habría que discriminar, en todo caso, si este proceso de implantación fue conscientemente planificado o vino dado por el azar. Lamentablemente, las fuentes que hoy en día están abiertas al investigador no ofrecen vías para dilucidar esta cuestión.

26 Vascongado se aplicaba generalmente sólo a los naturales de las provincias de Álava, Guipúzcoa y Vizcaya; vasco, por su parte, pasó de definir a los naturales de la Euskal Herria perteneciente a Francia, a denominar al total de los vascos, de un modo más neutro.

27 Euzkotarra: Aberri, 12 de junio de 1923.

28 Etxebarria, Isaac de: Euzkadi, 16 de febrero de 1932. 
ral, al hablar de ideas generales sobre el alto número de personas que partían a América desde Euskal Herria, no se trasluce este tipo de distinciones: todos son vascos. Será luego, en su actuación allá, y en especial en la vinculación que mantengan con su país de origen — desde el análisis de la ideología político-patriótica de los emigrantes-, cuando serán definidos desde una visión de la colectividad vasca, reducida ya casi en exclusiva a la nacionalista.

De este modo, y prácticamente desde principios de siglo, la imagen ofrecida por la prensa nacionalista a sus lectores en el País Vasco sobre el devenir de sus connacionales radicados en Ultramar fue sesgada, parcial y lineal, ofreciendo la impresión de una sociedad vasco-americana casi exclusivamente nacionalista, cuya homogeneidad no se vería empañada sino por los lamentos ante los pocos vascos que aún hacían oídos sordos a la llamada de su patria y su sangre. Especialmente en el caso de Argentina, en el que nos vamos a centrar, la imagen es casi monolítica: todo gira alrededor de los nacionalistas, todo es aranismo, excepto sendas menciones - dos en treinta años- a los "vascongados" de Buenos Aires y a la formalización de su escisión en el centro "Gure Echea" de la capital argentina. ${ }^{29}$

Esta visión ofrecida contrasta, sin embargo, con la realidad del propio desarrollo de la colectividad vasca en Argentina, en la que el nacionalismo vasco tuvo una difusión lenta y laboriosa, con altibajos, hasta su definitiva victoria como ideología oficial de casi todos los centros vascos del país a partir de 1940. Tras unos primeros años, entre 1903 y 1909, de rápida difusión, la década de 1910 fue un período nefasto para el nacionalismo, que se vio dominado por una reacción de los vascos españolistas, los cuales se hicieron con el control del más antiguo e importante centro vasco del país, el "Laurak Bat" de Buenos Aires. Sólo a partir de 1922, tras la ruptura definitiva entre ambos sectores, los nacionalistas se quedarían con el mando de los centros vascos tradicionales, que se verían renovados, tras unos años de leve languidecimiento, con el aporte del más politizado exilio originado por la Guerra Civil española. ${ }^{30}$

A pesar de todo, el análisis de la propia prensa nacionalista da pistas para poder apreciar este proceso, aunque siempre desde la visión pro-nacionalista y parcial que hemos mencionado. Es interesante obser-

29 Ídem. También Etxebarria, Isaac de: Euzkadi. 11 de marzo de 1931.

30 Álvarez Gila, O.: “Euskal...”, págs. 83-86. 
var el período de relativo silencio sobre la actividad de los centros vascos de Argentina durante la década de 1910. Así, por ejemplo, tras una profusa aparición de noticias sobre el "Zazpirak Bat" de Rosario correspondiente a sus primeros años, con el adormecimiento de su nacionalismo quedó oscurecida su presencia como objeto noticiable, no mejorando hasta 1923, tras la recuperación de su dirección por elementos nacionalistas. ${ }^{31}$ Los años españolistas de este centro, al igual que los del "Laurak Bat", fueron simplemente silenciados. Sólo la sociedad de socorros mutuos "Euskal Echea" - apolítica pero cercana al concepto geográfico más completo del País Vasco, ${ }^{32}$ y por tanto, más del agrado de la visión nacionalista - sería objeto en este tiempo de una atención regular. ${ }^{33}$ Una vez impuesto el nacionalismo, la comunicación se hará de forma más fluida y la colectividad "vasca" en Argentina, como otras de América, recuperará su pequeño espacio en el noticiero de la prensa nacionalista editada en Euskal Herria.

\section{Los lamentos por la emigración}

Finalmente, el tercer pilar de la visión nacionalista de la emigración consistía en un lamento genérico por su misma existencia. La corriente migratoria, en un planteamiento nada original ya puesto en evidencia por otras voces a lo largo del XIX, suponía para los nacionalistas una auténtica sangría para el país de origen, por la pérdida de los más jóvenes y robustos brazos, lo que vendría en deterioro de la economía vasca ${ }^{34}$ Los nacionalistas añaden, sin embargo, un matiz propio a este planteamiento clásico: la corriente migratoria también suponía para Euskal Herria una pérdida difícilmente reparable desde el punto de vista étnico o de la pureza de la raza; debilitada la raza vasca frente a la latina - españoles y franceses-, al ser esta última más numerosa y por tanto más poderosa, con la marcha

31 Artazu, Juan de: "El nacionalismo vasco en la Argentina", Aberri, 12 de junio de 1923. La reconquista del centro Zazpirak Bat por los nacionalistas llevará, inmediatamente, a la liquidación de la sociedad creada como medio de enfrentamiento al españolismo por los mismos que dieron vida al Zazpirak Bat, el Euzko-Batzokija de Rosario. Artazu, Juan de: "El nacionalismo vasco en la Argentina. Liquidación de Euzko Batzokija", Aberri, 31 de julio de 1923.

32 Reunión de las siete provincias tradicionales de Euskal Herria, tanto las pertenecientes a España como las integradas en Francia.

33 Euzkadi, 9 de octubre de 1913, 13 de diciembre de 1915, 24 de febrero de 1919.

34 Kizkitza: Euzkadi, 12 de diciembre de 1924. 
de los auténticos vascos se favorecía la entrada en el País de elementos extraños, inmigrantes maketos que llegaban atraídos por un período de auge industrial, a falta de brazos autóctonos. ${ }^{35}$

Bien es cierto que se reconoce el derecho que asiste a toda persona a buscar fuera de su tierra natal mejoras en sus perspectivas económicas. Esto se hace especialmente palpable al analizar a los emigrantes vasco-franceses procedentes de una región, donde no existe una industria equiparable a la vizcaína o guipuzcoana que pudiera servir de destino natural a la superpoblación del agro. ${ }^{36}$ Pero, en el caso de los vascos de la vertiente española, era preferible un movimiento poblacional interno al país antes que su expatriación definitiva.

De todos modos, no hemos de pensar que el nacionalismo vasco renegara de la labor hecha por los vascos afincados en tierras americanas. En ciertos articulistas puede entreverse un orgullo por los adelantos económicos y sociales logrados por los más destacados de los emigrantes vascos en América ${ }^{37}$ Desde la prensa nacionalista se recurrió incluso a la historia para ensalzar la labor de los vascos - $\mathrm{O}$ sus descendientes - en diversos hitos de la historia americana: la evangelización —el obispo fray Juan de Zumárraga - ${ }^{38}$ la defensa de los indígenas —Pedro de Rentería, colaborador del padre Bartolomé de las Casas-, y sobre todo la Independencia entre otros Urdaneta, el emperador Iturbide e incluso el pretendidamente vasco Simón Bolívar. ${ }^{39}$

En ciertos momentos, además, el sueño americano llegó a considerarse como un buen colchón económico para el sostenimiento de la lucha patria, de igual modo a lo que estaba ocurriendo con uno de los ejemplos más seguidos por el nacionalismo vasco: Irlanda; los años posteriores a la Guerra Civil, cuando América se convirtió en el refugio natural para la corriente de exiliados nacionalistas que hubo de abandonar Euskal Herria tras la derrota republicana, vendrían a mostrar en buena medida la realidad de este aserto.

35 Ibídem, 15 de febrero de 1924.

36 Ariztimuño, José de: Euzkadi, 16 de marzo de 1934.

37 Kizkitza: Euzkadi, 20 de mayo de 1926.

38 Ibídem, 17 de agosto de 1926.

39 Utare: Bizkaitarra, 5 de noviembre de 1910. Baraibar, Carlos de: Aberri, 24 y 26 de julio de 1923, 4 de agosto de 1923. Kizkitza: Euzkadi, 14 de noviembre de 1924. La vinculación afectiva de un nacionalista vasco con personajes independentistas, destacados en la emancipación de las Américas frente al poderío español, era más que evidente. Quizá por esta razón no aparecerán reseñas sobre la memoria de otros personajes de origen vasco que también protagonizaron aquel periodo, pero en el bando contrario, de parte de España. 


\section{Periodización de las referencias sobre la presencia vasca en América en la prensa nacionalista}

Como comentábamos al principio, no todos los diarios cercanos al espectro político del nacionalismo vasco tratan el tema de la emigración de igual forma. El diario bilbaíno Euzkadi, desde su posición de portavoz oficial del partido, pudo hablar del fenómeno de la emigración vasca con mayor claridad de planteamiento nacionalista que otros diarios cuya función era distinta, como es el caso, por ejemplo, del diario deportivo Excelsior. Por ello, evidentemente fue Euzkadi quien más atención llegó a dedicar a este tema.

Dos son los períodos concretos en los que se aprecia una altísima concentración de referencias periodísticas y artículos sobre los vascos de América en la prensa nacionalista.

El primero de ellos es el sexenio 1923-1929, correspondiente en España a la dictadura del general Primo de Rivera. ${ }^{40}$ En este período se persiguió a las organizaciones nacionalistas, tanto catalanas como vascas, por lo que éstas tuvieron que transformarse, en la mayoría de los casos, en entidades de carácter cultural o deportivo, si querían seguir subsistiendo. Esta situación, reflejada en la prensa, llevó a la necesidad de tener que prescindir en gran medida de la información política nacional y, sobre todo, de cualquier referencia a la actividad política nacionalista en España. De este modo, los periódicos filonacionalistas adoptaron el recurso a las informaciones "extranjeras", entre las que destacaban sin duda las reflexiones, noticias y comentarios sobre la actividad de sus correligionarios en tierras americanas, de tal forma que la censura entonces vigente pudiera ser eludida y no existieran motivos para la suspensión de los periódicos..$^{41}$ Por otro lado, fue éste un momento de especial florecimiento de la familia nacionalista en Argentina —el país que recogía el núcleo de la expansión ultramarina del PNV—, tras la recuperación del control de los centros vascos del país.

40 Ben-Ami, Shlomo: La dictadura de Primo de Rivera (1923-1930), Barcelona, 1983. Para el caso vasco, Ramos, Cipriano: "El nacionalismo durante la dictadura de Primo de Rivera", Letras de Deusto, 31, Bilbao, 1985.

41 Fernández Clemente, Eloy: "La dictadura de Primo de Rivera y la prensa", Metodología de la Historia de la Prensa Española, Madrid, 1982, págs. 187-232. Santoja, Gonzalo: Del lápiz rojo al lápiz libre. La censura de la prensa y el mundo del libro, Barcelona, 1986. Seoane, María Cruz: "El régimen de censura bajo la dictadura de Primo de Rivera: efectos secundarios", La prensa en los siglos XIX y XX. Metodología, ideología e información, Bilbao, 1986, págs. 233-243. 
Pero, sin duda, el momento realmente floreciente para la presencia de los vasco-americanos en las páginas de la prensa nacionalista se produjo tras la proclamación de la Segunda República española y la "fiebre política" que siguió durante los años de régimen republicano hasta la Guerra Civil; de hecho, prácticamente la mitad de las referencias obtenidas corresponden al quinquenio 1931-1936.

Aunque en el régimen republicano siguió funcionando, en ocasiones, la censura, era evidente una mayor libertad de expresión, por lo que podía volverse a escribir en una clave más claramente nacionalista en el bloque de prensa afín al PNV. Las referencias a América son más militantes y se hallan mucho más ligadas a la realidad efervescente que vivía Euskal Herria, en busca de una autonomía cada vez más cercana. Ya no sólo había que contar con el vasco de Europa para trabajar en aras de la independencia del país; muchos vascos de América — se alegraba "Lantzi" - también habían hecho suyo este ideal. ${ }^{42}$ Las referencias a la renacida delegación argentina del PNV, la "Acción Vasca de Argentina", se vuelven más profusas; ${ }^{43}$ el Congreso Eucarístico que se celebra en 1934 en Buenos Aires sirvió para enviar a Argentina una delegación propagandística nacionalista. ${ }^{44}$ Incluso hubo ocasión de palpar en Euskal Herria, de forma directa, la potencia del nacionalismo vasco en América con el viaje propagandístico realizado por Juan de Zabala, destacado dirigente de "Acción Vasca de la Argentina", un indiano que recorrió el País Vasco en 1931 pronunciando conferencias y actuando en mítines sobre la actuación de los vasco-argentinos militantes nacionalistas; ${ }^{45}$ posteriormente volvió a América, donde siguió trabajando en la difusión del aranismo entre los emigrados y sirvió de apoyo a la instalación de los exiliados de la Guerra Civil. ${ }^{46}$

42 Lantzi, Euzkadi, 4 de mayo de 1933.

43 Acción Vasca era la Junta Extraterritorial del PNV en Argentina. Por impedimentos legales funcionaba cara a la legislación argentina como un centro cultural. Tenía su sede en la calle Córdoba 2028, de Buenos Aires. Aparece nombrada principalmente en la sección "carnet político" del diario Euzkadi.

44 Entre otros, Euzkadi, 5 de diciembre de 1934.

45 Sobre la trayectoria de Zabala puede verse Euzkadi, 8, 21, 28 y 30 de julio de 1931, 8 de agosto de 1931, 26 de septiembre de 1931, 16 y 17 de febrero de 1932, 1 y 8 de mayo de 1934. Además de éstas, Euzkadi recoge otras muchas más referencias a sus actuaciones políticas en el País Vasco, sobre todo en noticias cortas, a lo largo de 1931.

46 Centro de Documentación de Historia Contemporánea del País Vasco (San Sebastián), Fondo Manuel Irujo, Archivador n ${ }^{\circ}$ 64, fol. $\mathrm{n}^{\circ} 282$. 


\section{Distribución de las noticias por países y temática}

Para finalizar nuestro análisis, antes de ofrecer la lista de artículos sobre la presencia vasca en América que hemos encontrado en la prensa nacionalista, conviene realizar una pequeña mención a los países americanos a los que se refieren.

La geografía así obtenida deja entrever un hecho que sólo recientemente ha comenzado a ser corroborado por la historiografía especializada en la emigración vasca ultramarina, pero que ya era conocido desde tiempo atrás por cierta tradición oral: la mayor presencia vasca en Argentina, Uruguay, Chile y México, que en otras zonas del continente. Precisamente es a estos países a quienes está dedicada la mayor parte de los artículos de prensa recensados. Entre ellos, Argentina es la nación a la que más atención se dedica; fue, también, el país con mayor presencia de vascos nacionalistas antes de 1940.

En cuanto a la temática de dichos artículos, son los apartados que hemos denominado "nacionalismo vasco" y "colectividad vasca" los que agrupan más de la mitad de las informaciones. Se corresponde con la lógica, dado el carácter de prensa ideológica que tenía la nacionalista, que usa en gran medida las noticias ofrecidas por los vascos de América como modo de mostrar nuevas imágenes sobre la potencia y difusión de su propio ideario político. De hecho, buena parte de las referencias que hemos encuadrado en "colectividad vasca" — que recoge la presencia institucional vasca en América- están dedicadas a instituciones nacionalistas y proclives al nacionalismo o, a lo sumo, a centros indiferentes políticamente o no militantemente antinacionalistas. De igual modo, son de destacar los breves pero enjundiosos artículos en los que se expresa la idea nacionalista sobre el proceso emigrador, destacando por su calidad los firmados por el sacerdote y famoso escritor euskérico José de Ariztimuño "Aitzol". 


\section{Apéndice}

\section{Relación cronológica de las referencias a la emigración vasca a América y la presencia vasca en América en la prensa nacionalista (1900-1936)}

(Entre corchetes: resumen temático del contenido del artículo)

1909, enero 23, Bizkaitarra. Kepa: “Histórico ¡No lo pueden negar! ¡Donde hay obreros vascos no hay problemas!" [Tomado de la revista vasca Aurrera de Chile].

1909, abril 10, Bizkaitarra. "Los cuentos de JEL en América" [Copiado de El Tiempo, diario católico de México, sobre el heroísmo caritativo de las mujeres vascongadas $]{ }^{47}$

1909, mayo 6, Bizkaitarra. Urrutia’tar, Rrikarta: “Carta de Cuba” [Inauguración del "Euzkotar Batzokija"48 de La Habana].

1909, mayo 6, Bizkaitarra. "A los suscriptores del extranjero" [Relación de suscriptores de este periódico en México, Argentina, Chile, Cuba y Filipinas].

1909, mayo 19, Bizkaitarra. [Se reproduce la nota anterior].

1910, enero 22, Bizkaitarra. Berroeta Aldamar: "Desde México. Más sobre centros vascos".

1910, abril 9, Bizkaitarra. "De Administración" [Sobre las suscripciones a este periódico formalizadas desde América].

1910, octubre 10, Bizkaitarra. Urrutia, Eduardo de: "Emigración vasca" [Comentario de libros escritos sobre la emigración vasca].

1910, noviembre 5, Bizkaitarra. Utare: "La independencia de América. Acción de un nabarro".

1910, noviembre 19, Bizkaitarra. "Sección Nazkaldija. ${ }^{49}$ La emigración".

1910, diciembre 3, Bizkaitarra. A’tar, E.: "Francisco Madero. R. Argentina" [Sobre la fundación de un batzoki en la localidad argentina de Francisco Madero].

1910, diciembre 3, Bizkaitarra. "Sección Nazkaldija. La emigración" [Diversas conmemoraciones de la muerte de Sabino Arana en América].

1910, diciembre 24, Bizkaitarra. "Sección Nazkaldija. ¡Nos iremos a América!" [Lamento sobre la despoblación del País Vasco].

47 JEL (Jaungoikoa eta Lagi Zarra: Dios y Fueros) es la divisa del nacionalismo aranista.

48 Euzkotar Batzokija o Batzokia es el nombre que adoptaron las sedes locales del PNV. Pronúnciese "batzokiyá".

49 Nazkaldija (pronúnciese nazkaldiyá) significa miscelánea en lengua vasca. 
1913, mayo 15, Euzkadi. "Ecos simpáticos de La Baskonia” [Reseñas tomadas de la revista vasca "La Baskonia" de Buenos Aires].

1913, agosto 28, Euzkadi. Gandiaga Loyola, Ander: "Euzko Etxea. ${ }^{50}$ Sobre la fundación de Euzko Etxea" [Centro vasco de México].

1913, septiembre 6, Euzkadi. Euskotarra: "Los nacionalistas vascos en la Argentina. Las fiestas de San Ignacio por la mañana. Solemnes cultos" [Organizadas por el centro vasco de Rosario].

1913, septiembre 9, ibídem. "Fiestas de San Ignacio por la tarde" [Continuación del anterior].

1913, septiembre 22, Euzkadi. "Mexiko'tik. Bagabiltza"s1 [Sobre la difusión del nacionalismo vasco en la colonia emigrante en México].

1913, septiembre 25, Euzkadi. Euskotarra: "Los nacionalistas vascos en la Argentina. Amor y paz" [Sobre el centro vasco "Zazpirak Bat" de Rosario].

1913, octubre 9, Euzkadi. "Crónica de la Argentina" [Crónica de un festival vasco en el colegio Euskal Echea de Llavallol, Buenos Aires].

1914, marzo 20, Euzkadi. "De Cuba. Las Fiestas del Colegio de Belén. Compra de la refinería de Cárdenas. El Centro Eúskaro. La Fiesta de $\mathrm{N}^{\mathrm{a}}$ Señora de Begoña" [Fiesta vasca celebrada por el centro vasco de La Habana, Cuba].

1914, marzo 31, Euzkadi. Akullo: "El Centro Vasco de México".

1914, abril 11, Euzkadi. Basabil: "De la Argentina. Sobre la emigración de vascos a la Argentina" [Ideología nacionalista sobre la emigración].

1914, junio 15, Euzkadi. Basabil: "Crónica de Uruguay. Monumento a Bruno Mauricio de Zabala" [Vasco fundador de la ciudad de Montevideo].

1914, octubre 16, Euzkadi. Neu: "Desde México. Las Fiestas de la Independencia. Próxima evacuación de Veracruz por las tropas norteamericanas. Matrimonio vasco".

1915, mayo 17, Euzkadi. F.E.S.: "Gran filósofo vasco. El maestro Fray Francisco de Vitoria y la conquista de América".

1915, agosto 25, Euzkadi. Omikron: “Acción Vasca. Los vascos en América y el proyecto de Toponimia" [Sobre un proyecto de recoger la toponimia vasca en América, apadrinado por "Acción Vasca de la Argentina”].

1915, septiembre 20, Euzkadi. Elizetxe'tar, Joseba: "Noticias de México. Interesantes relatos de un caballero nabarro".

1915, diciembre 13, Euzkadi. Basabil: "Los Vascos en América. Festival vasco de Euskal Etxea" [Crónica de un festival vasco en el colegio Euskal Echea de Llavallol, Buenos Aires].

1916, enero 12, Euzkadi. Zuya: "Desde Buenos Aires" [Crítica sobre la representación de la comedia "Nerea" el 12 de diciembre de 1915 por el centro vasco de Buenos Aires].

50 Euzko Etxea significa "Casa Vasca".

51 En euskera: "Desde México. Caminamos". 
1917, enero 7, Euzkadi. Arteche Arana, L.: "Crónicas de Cuba" [Informaciones varias sobre la colonia vasca en la isla de Cuba y la ciudad de La Habana].

1917, septiembre 14, Euzkadi. Azpeitia, Enrique de: "Los Vascos en México".

1918, marzo 9, Bizkaitarra. T.: "Encauzar las energías" [Ideología nacionalista].

1919, febrero 24, Euzkadi. Rina, Francisco de: "Los Vascos en México" [Adhesión en México a la autonomía vasca y catalana. Críticas al presidente del Centro Vasco].

1919, junio 9, Euzkadi. Bikotx: "Los Vascos en América" [Defensa del nacionalismo vasco. Su expansión por América].

1919, agosto 9, Euzkadi. "Fiestas vascas en Buenos Aires" [Organizadas por el centro Laurak Bat].

1919, agosto 11, ibídem. Continuación.

1919, diciembre 17, Euzkadi. Ordoitz: "De la República Argentina. En Euskal-Etxea" [Fiesta vasca en el colegio Euskal Echea de Llavallol].

1921, abril 6, Euzkadi. Etxeberria, Isaac: "Los vasco-argentinos y la cultura nacional" [Sobre el mantenimiento del carácter vasco entre los hijos de emigrantes].

1921, agosto 19, Euzkadi. Burdindogi: "Egunekua. Argentina'ko gaurko idazkija, arren, irakurri barik ez itzi. Aberri egun bat Argentinan". ${ }^{52}$

1921, septiembre 10, Euzkadi. Albontsa y otros: "Egunekua. Txile'ko izpar-aberrikoyak" ${ }_{53}$ [progresos de los nacionalistas vascos en Chile].

1923, junio 12, Aberri. Artazu, Juan de: "El Nacionalismo Vasco en la Argentina".

1923, junio 19, ibídem. [Recordando la fundación del "Euzko Batzokija" de Rosario].

1923, junio 28, ibídem. [Sobre el manifiesto del Comité Nacionalista Vasco de la Argentina ${ }^{54}$ en abril de 1908].

1923, julio 18, Aberri. "Desde Rancagua" [sobre la difusión del diario "Aberri” en Rancagua, Chile. Número de suscripciones].

1923, julio 24, Aberri. Baraibar, Carlos de: "La raza vasca por el mundo. Simón de Bolíbar, libertador".

1923, julio 26, Aberri. Baraibar, Carlos de: "Simón Bolíbar, el libertador. Su juventud hasta la proclamación de la independencia americana".

1923, julio 31, Aberri. Artazu, Juan de: "El Nacionalismo Vasco en la Argentina" [Liquidación de la sociedad "Euzko Batzokija" de Rosario por su decadencia].

1923, agosto 4, Aberri. Baraibar, Carlos de: "Simón de Bolíbar, el libertador. Triunfo y destierro de Bolíbar. Su apogeo en el Congreso de Angostura”.

52 "Del día. No dejar sin leer, por favor, la reseña de Argentina de hoy. "Aberri Eguna" [Día de la Patria Vasca] en Argentina".

53 "Del Día. Noticias patriotas de Chile".

54 Primer centro nacionalista fundado oficialmente en Argentina, precedente directo de AVA. 
1923, agosto 12, Euzkadi. Kizkitza: "Los vasco-argentinos y Enbeita” [Bertsolari vasco, que recibió ayuda económica de los emigrantes vascos de Argentina].

1923, agosto 22, Aberri. Artazu, Juan de: "El Nacionalismo Vasco en la Argentina". [Creación del "Argentina Buru Batzar" del PNV y su Junta Municipal de Buenos Aires. ${ }^{55}$ Fiesta vasca en Bahía Blanca].

1924, mayo 24, Euzkadi. Bollar, S. B.: "El entierro de un vasco en América".

1924, junio 7, Euzkadi. "Euskal Echea. La excelente labor de nuestros hermanos de América" [Historia y función que cumple esta sociedad de socorros mutuos entre los vascos de Argentina].

1924, julio 22, Euzkadi. "Los Padres Blazy y Donostia en Buenos Aires". ${ }^{56}$

1924, septiembre 3, Euzkadi. K.: "Grandiosa institución de un vasco. Juan de Anchorena" [Emigrante vasco en Argentina].

1924, noviembre 2, Euzkadi. "Cabanas Oteiza" [Referencias de la prensa americana sobre la gira que hizo este pintor vasco por aquel continente].

1924, noviembre 14, Euzkadi. K.: "El libertador" [Sobre el origen vasco del apellido Bolívar].

1924, diciembre 5, Euzkadi. K.: "Sobrepoblación vasca en América" [Sobre el empobrecimiento "racial" que sufre Euskal Herria por la emigración, con cifras].

1924, diciembre 13, Euzkadi. K.: "Mejor un hogar que un imperio" [La emigración como responsable de la pobreza económica y racial del pueblo vasco].

1924, diciembre 25, Euzkadi. "Artistas vascos. Cabanas Oteiza y la crítica argentina".

1925, mayo 22, Euzkadi. Garaztarra, Michel:57 "Los Vascos en Necochea" [Tomado de la revista "Euskalduna" de Buenos Aires].

1925, mayo 24, Euzkadi. "El entierro de un vasco en América".

1925, julio 3, Euzkadi. "La conquista de América y Vitoria, el filósofo vasco".

1925, agosto 1, Euzkadi. M. de L.: "Euskal Echea de Llavallol. Vascos de acá y vascos de allá" [Sobre la labor de este colegio vasco de Argentina].

1925, septiembre 5, Euzkadi. Garaztarra, Michel: "El pintor vasco Mújica en Buenos Aires".

1925, noviembre 26, Euzkadi. "Los Vascos en América. Grandioso festival de fin de curso en Euskal Etxea" [Colegio vasco de Argentina].

1926, enero 10, ibídem. [Párrafos del libro de Tomás Otaegui, "Derecho de gentes argentino"].

55 El "Buru Batzar" (Junta Rectora provincial) y la Junta Municipal son las dos instituciones clave de la organización del PNV en el propio País Vasco.

56 Estos dos sacerdotes, secular vasco-francés el primero y capuchino navarro el segundo, hicieron en 1924 un recorrido por Argentina a fin de obtener fondos de los vascos de América para la construcción de un nuevo seminario menor para la diócesis vasco-francesa de Bayona, en la localidad labortana de Ustaritz.

57 Seudónimo del periodista vasco-francés Michel Iriart, que desarrolló toda su labor periodística en Argentina. 
1926, febrero 14, Euzkadi. "Las Reducciones Sudamericanas" [La participación de los vascos en las misiones jesuíticas].

1926, febrero 17, Euzkadi. "Los vascos fundadores de la Argentina" [Párrafos del libro de Tomás Otaegui, "Derecho de gentes argentino"].

1926, mayo 20, Euzkadi. Kizkitza: "Blanca y azul. Esperanzas" [Sobre la labor de los emigrantes vascos en el florecimiento de Argentina].

1926, agosto 17, Euzkadi. K.: "Fray Juan de Zumárraga. Salvador de la raza india".

1926, agosto 20, ibídem. "Fray Juan de Zumárraga. Gran prelado".

1926, agosto 29, Euzkadi. "Los Vascos en América" [Fines, historia y futuro del centro "Euskal Erria" de Montevideo].

1926, septiembre 1, Euzkadi. K.: "Vascos en la Historia. El Padre Las Casas y Pedro de Rentería".

1926, septiembre 14, Euzkadi. Garaztarra, Michel: "Arte vasco en Buenos Aires".

1927, abril 7, Euzkadi. Kizkitza: "Los Vascos en América" [Sobre el peligro que sufre la cultura y raza vascas, por la presión de la raza latina, más fuerte].

1927, julio 23, Euzkadi. Otaegui, Tomás de: "Los Vascos en América. La fundación de Buenos Aires y la intervención vasca vista por el Dr. Tomás de Otaegui en la revista La Baskonia" [de Buenos Aires].

1927, agosto 9, Euzkadi. Kizkitza: "Simón Bolívar, el libertador".

1927, octubre 10, Excelsior. "Los españoles repatriados en Cuba".

1927, octubre 20, Euzkadi. Kizkitza: "Pizarro. Bolívar".

1927, noviembre 10, Excelsior. "Para atender a la conducción de los emigrantes" [Acciones del gobierno brasileño].

1927, diciembre 11, Excelsior. "Chile reclama corriente migratoria".

1928, marzo 8, Euzkadi. Echevarri, Luis: "Cartas de la Argentina. La prensa vasca en los Países del Plata".

1928, marzo 31, ibídem. Un explorador vasco sigue las huellas de la raza roja" [Sobre el vasco-argentino Florencio de Basaldúa].

1928, abril 26, Euzkadi. M.P.: "Nicolás Mújica en América" [Visita a América de este pintor vasco].

1928, abril 28, Euzkadi. Echevarri, Luis: "Cartas de la Argentina. La colectividad vasca en los países del Plata" [Sobre centros vascos y el interés de los vascos americanos por conservar su cultura].

1928, mayo 8, Euzkadi. Kizkitza: "Los Vascos en Europa y América" [Sobre la dispersión del pueblo vasco, clave de su debilidad. Se detecta poco amor a lo vasco entre los vasco-argentinos].

1928, junio 1, Euzkadi. Echevarri, Luis: "Cartas de la Argentina. Una peregrinación vasca a Luján".

1928, julio 1, Euzkadi. "La huella de los vascos en la sociedad argentina" [Lamenta que no apliquen su situación económica favorable a las actividades patrióticas]. 
1928, agosto 22, Euzkadi. Echevarri, Luis: "Cartas de la Argentina. Una tarde vasca en Buenos Aires" [Exposición de pintores vascos en Buenos Aires].

1928, octubre 25, Euzkadi. Echavarri, Luis: "Cartas argentinas. Los Vascos en América. La nueva capilla de Euskal Etxea, en Llavallol".

1928, noviembre 1928, Euzkadi. Atxika-Allende, Alberto de: "Los Vascos por el mundo. De ganadería argentina".

1928, diciembre 30, Euzkadi. "Notas al margen. La emigración aldeana" [Ideología nacionalista sobre la emigración a América].

1929, enero 8, Euzkadi. Arana, José Domingo de: "Los Vascos en América" [Réplica contra la idea de que los vascos de América son antivascos].

1929, enero 26, ibídem. [Las razones de la emigración].

1929, enero 29, ibídem. [Loas a la República Argentina y a la población vasca que colabora en su carácter liberal. Fundación de batzokis vascos en Argentina].

1929, mayo 25, Euzkadi. "Ultrabidasoa, Ibarnegaray" [Viaje de este diputado vasco-francés a Argentina].

1929, junio 5, Euzkadi. Kizkitza: "Los vascos, en América, Dispersión y convivencia" [Necesidad de que los vascos mantengan pura su estirpe en América].

1929, julio 5, Euzkadi. "Los vascos en América. Dispersión y convivencia".

1929, julio 22, Euzkadi. Enraibi: "Ultrabidasoa. Al tornar de la Argentina" [Viaje del diputado vasco-francés Ibarnegaray a Argentina].

1929, agosto 1, Euzkadi. Kizkitza: "Euskeldun y triunfador" [Vuelta de emigrantes vascos o indianos desde EE.UU. y Argentina].

1931, marzo 11, Euzkadi. Etxeberria, Isaac: "Vascos y vascongados" [Disputas entre vascos nacionalistas y carlistas en Argentina].

1931, agosto 1, Euzkadi. "Carnet político. Fiesta de la Juventud Vasca [de Bilbao]. La cooperación de los vascos en la Argentina” [Regalo de una bandera vasca a Juventud Vasca por los vascos nacionalistas de Buenos Aires].

1931, agosto 2, 3 y 4, Euzkadi. "Conferencia dada la noche del 30 de julio de 1931 por D. Alberto de Atxika-Allende en Juventud Vasca de Bilbao" [Sobre la bandera vasca regalada por los nacionalistas de Buenos Aires].

1932, enero 20, Euzkadi. "Los vascos en Caracas" [Inauguración de un frontón de Jai Alai]..$^{58}$

1932, enero 22, Euzkadi. "Carnet político. Gure Etxea de la Argentina”.

1932, febrero 16, Euzkadi. Etxeberria, Isaac: "Los vascuences de Buenos Aires" [Sobre la apertura del centro "Gure Echea" 59 de Buenos Aires, escisión promovida por los no nacionalistas].

1932, abril 7, Euzkadi. "Usansolo'ko Euzko Batzokija” [Inauguración de la sede del PNV en Usansolo, Vizcaya, con asistencia de "nacionalistas de América"].

58 Deporte de pelota vasca, en modalidad de cesta punta.

59 En euskera, "Nuestra Casa". 
1932, abril 8, Euzkadi. Lizarreta: “Arrese'tar Emeteri nere lagun entzutetsuari Otaño'tar Pello Mari zanaren oroimenean. Aberri arazoak". ${ }^{60}$

1932, septiembre 20, Euzkadi. Izaurieta, José María: "Euzkadi en Argentina. Labor internacional" [Sobre "Acción Vasca de la Argentina"].

1932, octubre 22, Euzkadi. Lantzi: "Crónica de Chile. Festividad de Iñaki Deuna".

1932, octubre 29, Euzkadi. "Carnet político. Cómo acoge la prensa argentina las informaciones referentes a Euzkadi.

1932, noviembre 9, ibídem, "Nación Vasca"” [Revista de "Acción Vasca de la Argentina"].

1932, noviembre 11, Euzkadi. Atxika-Allende, Alberto de: "El corresponsal imaginario. El monje vasquista" [Sobre Dominique Sarrote, primer capellán de los vascos en Montevideo, 1852].

1932, noviembre 18, Euzkadi. "La pérdida de un ilustre patriota vasco. La muerte del doctor don Tomás de Otaegui causó en toda Euzkadi un profundo dolor. Se enviaron a Buenos Aires cablegramas de pésame".

1932, noviembre 20, Euzkadi. "Anoche en Juventud Vasca de Bilbao. En recuerdo del ilustre vasco doctor don Tomás de Otaegi".

1932, noviembre 28, Excelsior. "La Argentina prohibe la emigración".

1932, noviembre 30, Euzkadi. "Una hermosa respuesta del doctor Otaegi a los vascos de la Euzko Etxea". ${ }^{61}$

1932, diciembre 1, Euzkadi. "Otaegi y los vascos originarios" [Ponderando la figura de este vasco nacionalista nacido en Argentina].

1932, diciembre 24, Euzkadi. Erri: "Errijetatik. Chile'tik" [Noticias varias sobre vida social de los vascos en Chile].

1932, diciembre 28, Euzkadi. "Carnet político. Unas notas sobre el fallecimiento del doctor Tomás de Otaegi".

1933, enero 1, Euzkadi. Etxeberria, Isaac y José María de IZAURIETA: "Recordando al Dr. [Tomás] Otaegui".

1933, enero 15, Euzkadi. "Una hermosa iniciativa de un grupo de sacerdotes patriotas. Nuestro idioma en Chile" [Inicio de la "misa de los vascos" en Santiago de Chile].

1933, enero 21, Euzkadi. "Una carta del hijo del doctor Otaegi. Agradecimiento y adhesión".

1933, enero 21, Euzkadi. "Carnet político. La Prensa argentina y la muerte del doctor Otaegi".

1933, enero 24, ibídem. "Juicios de la Prensa argentina con motivo de la muerte del doctor Otaegi".

1933, enero 25, ibídem. "La Prensa argentina habla de la muerte del doctor Otaegi".

60 "A mi conocido amigo Emeterio Arrese, en recuerdo de quien fue Pello Mari Otaño [bertsolari vasco emigrante en Argentina]. Problemas de la patria".

61 Centro nacionalista vasco de Bilbao. 
1933, febrero 25, Euzkadi. Kizkitza: "Libertad y raza. América” [Sobre la lucha entre la raza latina y la raza vasca].

1933, mayo 4, Euzkadi. Lantzi: "Carta de América. Los Vascos en Chile" [Resurgir nacionalista de la colonia vasca. Agrupación de "Euzko Gaztedija"].

1933, junio 7, Euzkadi. "Carnet político. La bandera de Euzkadi ha ondeado en Montevideo" [Izada la bandera vasca en la sede de "Euskal Ordua"].

1933, junio 18, Euzkadi. Kizkitza: "Paraguayos y vascos" [Historia de las reducciones jesuíticas].

1933, julio 19, Euzkadi. "Carnet político. Euzkadi en Uruguay. La Prensa de Montevideo se ocupa extensamente de una fiesta vasca" [organizada por "Euskal Ordua"].

1933, septiembre 30, Excelsior. "Se limita la entrada de extranjeros en la Argentina".

1933, octubre 4, Euzkadi. Lantzi: "Carta de América. Los vascos en Chile" [Celebración de la fiesta de San Ignacio].

1933, octubre 5, Euzkadi. "Carnet político. La festividad de Iñaki Deuna en Manila" [Por la Agrupación Vasca de Manila, nacionalista].

1933, octubre 6, Euzkadi. "Iñaki Deuna en Manila".

1933, octubre 7, Euzkadi. "Carnet político. El doctor Atxika-Allende nos hablará esta noche en Juventud Vasca del doctor Otaegi".

1933, octubre 8, Euzkadi. Lantzi: "Carta de América. Los vascos en Chile" [Reseña sobre el pueblo vasco en el periódico "El Mercurio" de Santiago].

1933, octubre 13, Euzkadi. "Los vascos en Montevideo. Grandes fiestas con motivo de izarse la bandera bicrucífera en Euzkal-Erria" [Izado de la bandera vasca].

1933, octubre 13, Euzkadi. Itxosua: "Mensaje patriótico. Homenaje de los patriotas de Rosario de Santa Fe a la memoria de Sabino de Arana".

1933, octubre 14, Euzkadi. "De unas interesantes fiestas patrióticas organizadas por los vascos de Montevideo" [Izado de la bandera vasca].

1933, octubre 29, Euzkadi. "Interesantes fiestas vascas en Montevideo" [Izado de la bandera vasca (fotografía)].

1933, noviembre 2, Euzkadi. "Un importante diario chileno dedica seis páginas a Euzkadi [Reseña sobre el pueblo vasco en el periódico "El Mercurio" de Santiago].

1933, diciembre 1, Euzkadi. "Acción Nacionalista Vasca de la Argentina y el 25 de octubre" [Declaración patriótica de los nacionalistas de Buenos Aires en la fecha de la abolición foral].

1934, enero 7, Euzkadi. "Una plaza vasca en Santiago de Chile" [Actos de inauguración. Lista de la nueva junta directiva de "Euzko Gaztedija"].

1934, enero 25, Euzkadi. "Los vascos patriotas de Euzkal Erria de Montevideo". 
1934, febrero 24, Euzkadi. "Carnet político. Más sobre la obra de los vascos de América" [Sobre la sociedad de socorros mutuos Euskal Echea de Argentina].

1934, marzo 8, Euzkadi. "Una fiesta patriótica de Acción Nacionalista Vasca de la Argentina".

1934, marzo 11, Euzkadi. Lekue, Benedicto: "Los misioneros vascos. La muerte del Padre Iribertegi" [Misionero pasionista en la Amazonia peruana].

1934, marzo 11, Euzkadi. Relaciones exteriores del B.B.B.62 "Los vascos del Oregón".

1934, marzo 13, Euzkadi. "La posición del "Laurak Bat" de Buenos Aires, ante el Estatuto Vasco".

1934, marzo 15, Euzkadi. "Carnet político. Los nacionalistas vascos en Uruguay" [Fiestas patrióticas varias].

1934, marzo 22, Euzkadi. "La ley del 25 de octubre de 1839. Una interesante nota de Euzko Gaztedija de Santiago de Chile" [Protesta anual contra la ley abolitoria de los fueros vascos].

1934, marzo 24, Euzkadi. "Más sobre la obra de los vascos de América" [Sobre la sociedad de socorros mutuos Euskal Echea de Argentina].

1934, marzo 28, Euzkadi. "En Chile se ha bautizado con el nombre de "Euzkadi" a un vapor pesquero".

1934, abril 15, Euzkadi. "Fiesta vasca en Montevideo" [Organizado por Euskal Ordua]. ${ }^{63}$

1934, mayo 12, Euzkadi. Lantzi: "Los Vascos en Chile. Un patriota menos" [Sobre el fallecimiento de Tomás de Ocáriz].

1934, mayo 31, Euzkadi. "Un mensaje de "Zazpirak Bat" de Rosario, al presidente de la Generalidad de Catalunya".

1934, junio 12, Euzkadi. "Con motivo del encarcelamiento del señor Zabala. Un artículo del doctor don Tomás de Otaegui (G.B.)". ${ }^{64}$

1934, junio 13, Euzkadi. "Jesús de Zabala" [Presidente honorario de "Acción Vasca de Argentina"].

1934, junio 14, Euzkadi. "Comentario. Euzko Anaidia" [Iniciativa sacerdotal de atención espiritual al emigrante vasco en Argentina].

1934, julio 31, Euzkadi. "Ensayo de arte" [Artistas vascos en América].

1934, agosto 2, Euzkadi. "Los Vascos en el Mundo" [Cualidad de la raza y nacionalidad].

1934, agosto 2, Euzkadi. Un vasco: "La lucha de los vascos. El Congreso Eucarístico Internacional de Buenos Aires".

1934, agosto 8, Euzkadi. "Los vascos en América" [Nombramiento de Sebastián de Amorrortu como presidente de "Acción Vasca de Argentina"].

62 "Bizkaiko Buru Batzar". Órgano directivo provincial de Vizcaya del PNV.

63 "La Hora Vasca", en euskera.

64 Siglas de Goian Bego ("Descanse en Paz" en euskera). 
1934, agosto 10, ibídem. [Nombramiento de Regino de Galdós como presidente de Euskal Ordua de Montevideo].

1934, agosto 12, Euzkadi. "Carnet político. El homenaje de los "ikasles" al Dr. Otaegui".

1934, agosto 16, Euzkadi. "Acto de despedida" [Jesús de Zabala, nacionalista, marcha a Argentina].

1934, agosto 16, Euzkadi. "Página semanal a cargo de Bizkai'ko Ikasle Batza. ${ }^{65}$ En memoria del doctor Otaegui. Ante la próxima aparición de su obra inédita "Narraciones Vascas". Patriótico mensaje que los vascos residentes en Madrid envían al doctor Tomás Otaegui”.

1934, agosto 21, Euzkadi. Lantzi: "Los Vascos en Chile" [Fraternidad vasco-catalana en la fiesta de Sant Jordi entre el "Casal Catalá" y "Euzko Gaztedija" de Santiago].

1934, agosto 23, Euzkadi. "Contestación a un mensaje. Del doctor Otaegui a los "ikasles" vascos".

1934, agosto 23, Euzkadi. "Carnet político. Los vascos, en Uruguay" [Sobre "Euskal Ordua" de Montevideo].

1934, agosto 24, ibídem.

1934, agosto 30, Euzkadi. "Cena homenaje a Jesús de Zabala" [En su marcha a Argentina].

1934, agosto 31, Euzkadi. "Un libro del doctor Otaegui. Narraciones vascas".

1934, septiembre 1, Euzkadi. "Homenaje a Jesús de Zabala" [En su marcha a Argentina].

1934, septiembre 2, Euzkadi. "Un mensaje del Euzkadi Buru Batzar ${ }^{66}$ a los vascos de América" [Pide a los vascos de América que reciban el mensaje nacionalista que difundirá Jesús de Zabala].

1934, septiembre 3, Euzkadi. "La estancia de don Jesús de Zabala en Barcelona" [En su marcha a Argentina].

1934, septiembre 3, Euzkadi. "Carnet político. Los vascos, en México" [Gira artística de dos txistularis]. ${ }^{67}$

1934, septiembre 34, Euzkadi. Erri: "Chile'ko izparrak. Milpilla" [Noticias varias sobre vida social].

1934, octubre 3, Euzkadi. Arteche, José de: "Los Vascos en el Mundo. Uruguay" [Sobre el programa radiofónico de Montevideo "Euskal Ordua"].

1934, octubre 13, Euzkadi. "El rosario vasco. Fe y espíritu racial" [La religiosidad entre los vascos emigrados en América].

1934, octubre 24, Euzkadi. Lantzi: "Crónicas de Chile. Iñaki Deuna"68 [Celebración de San Ignacio por "Euzko Gaztedija" de Santiago de Chile].

\footnotetext{
65 "Asociación de Estudiantes de Vizcaya", en euskera. Es la rama estudiantil del PNV.

66 Máximo órgano directivo nacional del PNV.

67 Músicos que tocan el txistu, instrumento autóctono vasco de viento.

68 "San Ignacio", en euskera.
} 
1934, noviembre 14, Euzkadi. "Carnet político. Los vascos en el Uruguay” [Sobre "Euskal Ordua"].

1934, noviembre 16, Euzkadi. Ariztimuño, José de (“Aitzol”): “La emigración de ayer, la inmigración de hoy. Nuevo aspecto de un problema vasco" [Opinión nacionalista sobre los procesos migratorios en el País Vasco].

1934, noviembre 18, Euzkadi. "Los vascos, en Buenos Aires. Los expedicionarios vascos [al Congreso Eucarístico] hacen una excursión a Euskal-Echea".

1934, noviembre 18, Euzkadi. Ariztimuño, José de ("Aitzol"): "Causas de la emigración. Nuevo aspecto de un problema vasco" [Opinión nacionalista sobre los procesos migratorios en el País Vasco].

1934, noviembre 28, Euzkadi. Arantzadi, Engracio de: “Ana Luisa de Larrain” [Vasca residente en Chile].

1934, diciembre 5, Euzkadi. Ariztimuño, José de (“Aitzol”): “El emigrante derrotado y el indiano triunfador. Nuevo aspecto de un problema vasco" [Opinión nacionalista sobre los procesos migratorios en el País Vasco].

1934, diciembre 5, Euzkadi. "Los Vascos en la Argentina. Interesante conferencia del doctor don Teodoro de Ernandorena en Zazpirak-Bat de Rosario de Santa Fe".

1934, diciembre 9, Euzkadi. "En Acción Nacionalista de la Argentina" [Recepción a los vascos expedicionarios al Congreso Eucarístico].

1934, diciembre 11, Euzkadi. "Carnet político. Los vascos en Norteamérica. En Nueva York se celebra un homenaje a Sabino [Arana]".

1934, diciembre 11, Euzkadi. Ariztimuño, José de (“Aitzol”): "La emigración vasca y la poesía euskaldún. Venero de inspiración".

1935, enero 6, Euzkadi. "Dos artistas vascos a la Argentina [Viaje de Narciso de Balenziaga y Jorge Oteiza].

1935, enero 9, Euzkadi. "Carnet político. Los vascos en la Argentina. El aniversario de Sabino Arana en Buenos Aires" [Organizado por "Acción Vasca"].

1935, enero 11, Euzkadi. "Carnet político. Los vascos en la Argentina. De Acción Nacionalista Vasca de la Argentina".

1935, enero 16, Euzkadi. Lantzi: "Crónica de América. Los Vascos en Chile" [Diversas conmemoraciones de los vascos abertzales ${ }^{69}$ en Chile].

1935, enero 16, Euzkadi. "Un relato del señor Ernandorena. Los incidentes en la peregrinación al Congreso Eucarístico".

1935, enero 17, Euzkadi. "Los incidentes en la peregrinación al Congreso Eucarístico" [Continuación del anterior].

1935, enero 18, Euzkadi. "Los incidentes en la peregrinación al Congreso Eucarístico de Buenos Aires" [Continuación del anterior].

1935, enero 19, Euzkadi. Ariztimuño, José de ("Aitzol”): "Una dinastía de bertsolaris" [Sobre Pedro María Otaño, bertsolari ${ }^{70}$ guipuzcoano emigrante en Argentina].

69 "Patriotas", en euskera.

70 Improvisador de poesías orales en lengua vasca.

Tomo LIII, 1, 1996 
1935, enero 23, Euzkadi. Areso, Benito de: "Democracia vasca. La familia" [Sobre las causas que explican la emigración vasca].

1935, enero 25, Euzkadi. Urkiaga, Esteban de ("Lauaxeta"): "El Correo de la Argentina" [Sobre Mons. Leandro Astelarra, obispo argentino hijo de vascos].

1935, enero 26, Euzkadi. Lantzi: “Crónicas de Chile. El nuevo directorio de euzko Gaztedija y su programa. Algo sobre la política chilena".

1935, enero 29, Euzkadi. Atxika-Allende, Alberto de: "El corresponsal imaginario. El vasco, lo vasco y los vascos extra-euzkadianos".

1935, febrero 14, Euzkadi. Urkiaga, Esteban de ("Lauaxeta"): "Letras Vascas. Garoa” [Sobre el tratamiento de la emigración en la novelística en lengua vasca].

1935, marzo 20, Euzkadi. Erri: "Chile'tik". ${ }^{71}$ [Vida social en "Euzko Gaztedija"].

1935, marzo 27, Euzkadi. "Otro testimonio de duelo. Los vascos nacionalistas de Uruguay y la muerte de nuestro diputado don Ramón de Bikuña".

1935, abril 5, Euzkadi. "El escultor y su obra. Un magnífico busto del gran vasco-argentino Dr. Otaegui".

1935, abril 6, Euzkadi. "Los estudiantes vascos. El busto del Dr. Otaegui”.

1935, mayo 3, Euzkadi. Lantzi: "Crónica de Chile. Unas cifras alarmantes" [Sobre la mortalidad en Chile].

1935, mayo 9, Euzkadi. "Carnet político. Los vascos en la Argentina” [Sobre la revista "Nación Vasca", publicada por "Acción Vasca de Argentina"].

1935, mayo 9, Euzkadi. Enparantza'ko Gabin: "Ikasle-idazkija. Iparragirre" [Bertsolari vasco emigrante en América].

1935, junio 5, Euzkadi. "Carnet político. Los Vascos en la Argentina" [Sobre el centro "Zazpirak Bat" de Rosario].

1935, junio 9, Euzkadi. X.: "Los viejos nacionalistas. Del carlismo al nacionalismo" [Emigrante carlista vasco que se convirtió al nacionalismo].

1935, julio 6, Euzkadi. Lantzi: "Crónica de Chile" [Vida social en "Euzko Gaztedija"].

1935, julio 9, Euzkadi. Arteche, José de: "Comentario. Los vascos en el Uruguay" [Espíritu vasquista entre los emigrados directores de "Euskal Ordua"].

1935, junio 21, Euzkadi. Lantzi: "Crónica chilena. Aberri Eguna” [Celebración del Aberri Eguna ${ }^{72}$ en Chile].

1935, junio 22, Euzkadi. "Carnet político. Los vascos en la Argentina. Acción Nacionalista Vasca de Buenos Aires".

1935, junio 27, ibídem. "Zazpirak Bat” [Centro vasco de Rosario].

1935, julio 9, Euzkadi. Lantzi: "Crónica de Chile" [Noticias varias sobre: la misa de los vascos, cultura y vida social].

71 "Desde Chile", en euskera

72 "Día de la Patria [Vasca]", en euskera. 
1935, julio 9, Euzkadi. Artetxe, José de: “Comentario. Los vascos en el Uruguay” [Los problemas de la emigración].

1935, julio 11, Euzkadi. "Los vascos en Uruguay. Don Roberto García Quevedo, a Euzkadi. Un banquete en homenaje y despedida al director de "Euzkal Orduba"',

1935, julio 12, Euzkadi. "Los vascos en Uruguay. Don Roberto García Quevedo, a Euzkadi. Un banquete en homenaje y despedida al director de 'Euzkal Orduba", [Continuación del anterior].

1935, julio 14, Euzkadi. "Los vascos en la Argentina. Acción Nacionalista Vasca celebró varios actos conmemorativo del IV Euzkadi Eguna". ${ }^{73}$

1935, julio 18, ibídem. "Por la pacificación del Chaco" [Comunicado de "Acción Vasca de la Argentina" sobre la guerra paraguayo-boliviana].

1935, julio 21, ibídem. "En Acción Nacionalista Vasca de la Argentina".

1935, agosto 10, Euzkadi. "Los vascos en Uruguay. Un homeaje de Euzkal-Orduba al maestro Larrinbe (g.b.)".

1935, agosto 19, Euzkadi. "Los vascos en Nueva York" [Sobre el paso por Nueva York de dos misioneros capuchinos camino de Guam].

1935, agosto 17, Euzkadi. "Los vascos en la Argentina. El IV Euzkadi Eguna. Una exposición en Gure Etxea".

1935, septiembre 4, Euzkadi. "Carnet político. Los vascos patriotas de la Argentina" [Festividad de San Miguel].

1935, septiembre 5, Euzkadi. "Chile'ko Idaztijak. Iñaki Deuna eta Euzko Gaztedija" " [Festividad de San Ignacio por "Euzko Gaztedija" de Santiago de Chile].

1935, septiembre 8, Euzkadi. “Actividades de Euzkal Orduba” [Programa radiofónico vasco nacionalista de Uruguay].

1935, septiembre 26, Euzkadi. "Una exposición de Euzkal Orduba en Donostia" [Programa radiofónico vasco nacionalista de Uruguay].

1935, octubre 3, Euzkadi. "La biblioteca-caserío para Sudamérica. Una obra de solidaridad" [Proyecto cultural de Euskal Ordua de Montevideo].

1935, octubre 4 y 5, Euzkadi. "Un vasco-uruguayo ilustre. El doctor Etxegoyen, ministro de Instrucción Pública de Uruguay".

1935, octubre 17, Euzkadi. Lantzi: "Crónica de Chile. Los Vascos en América" [Noticias varias sobre: la misa de los vascos, cultura y vida social].

1935, octubre 24, Euzkadi. "Crónica de Chile. Fiestas de Iñaki Deuna en Santiago".

1935, octubre 27, Euzkadi. "Los vascos en la independencia del Uruguay. Conferencia de don Roberto García Quevedo".

1935, noviembre 2, Euzkadi. "Un homenaje a la República uruguaya. Un patriota vasco en el Uruguay.-El apóstol del árbol en el Río de la Plata._Figuras

73 "Día de Euzkadi”, en euskera.

74 “Crónicas de Chile. San Ignacio y Euzko Gaztedi”, en euskera. 
destacadas._Los vascos en el Uruguay: D. Zoilo Saldias, ministro de Industria y Trabajo.--Reseña histórica del Uruguay".

1935, noviembre 17, Euzkadi. "Los vascos en la Argentina. Acción Nacionalista Vasca de la Argentina suscribe un importante documento" [Protesta por el conflicto italo-etíope].

1935, noviembre 29, Euzkadi. "Carnet político. Ha muerto Narkis de Balenziaga" [Artista vasco conocido en Argentina].

1935, diciembre 15, Euzkadi. Artetxe, José de: "Comentario. Una historia de la emigración vasca".

1935, diciembre 15, Euzkadi. "Los vascos en la Argentina. La festividad del IV Euzkadi Eguna organizado por Acción Nacionalista Vasca revistió gran brillantez. Otras noticias".

1935, diciembre 18, Euzkadi. "Los vascos en el Uruguay. Don Ramón Juambeltz".

1935, diciembre 18, Euzkadi. Erri: "Chile'tik" [Noticias varias sobre vida social].

1935, diciembre 22, Euzkadi. Artetxe, José de: "Comentario. Una historia de la emigración vasca" [Continuación de un artículo anterior].

1935, diciembre 27, Euzkadi. Erri: "Chile'tik" [Noticias varias sobre vida social].

1935, diciembre 28, Euzkadi. "Interesantes actos celebrados por Acción Nacionalista Vasca de la Argentina".

1936, enero 1, Euzkadi. Koldobika: "Acción Nacionalista Vasca conmemora la festividad de Mikel Deuna" ${ }^{75}$ [Festividad de San Miguel en Argentina].

1936, enero 1, Euzkadi. "Los vascos en la Argentina. Importantes actos organizados para festejar el aniversario de Euzkaldun-Batzokija" [Centro político vasco de Buenos Aires].

1936, enero 2, Euzkadi. Koldobika: "Los vascos en la Argentina. Acción Nacionalista Vasca conmemora la festividad de Mikel Deuna" [Festividad de San Miguel en Argentina. Continuación de artículo anterior].

1936, enero 4, Euzkadi. Abertzale Bat: "Los vascos en Norteamérica. El Centro Vasco-Americano conmemora el XXXII aniversario de la muerte de Sabino [Arana]".

1936, enero 9, Euzkadi. "Los vascos en la Argentina. 'Nación Vasca"” [Prensa nacionalista vasca].

1936, enero 12, Euzkadi. "Los vascos en la Argentina. A la memoria del doctor Otaegui. Solemne entrega de la placa que el Consejo Supremo de Euzkadi ofrendó a la memoria del ilustre autor de 'Narraciones Vascas"'.

1936, marzo 10, Euzkadi. "Los vascos en el Uruguay. De la Junta Extraterritorial del PNV".

1936, abril 26, Euzkadi. Lantzi: "Por Correo. Los Vascos de Chile".

1936, agosto 9, Euzkadi. Uriarte, Juan de: “Crónica frontolera en México”.

75 "San Miguel", en euskera. 